(C) Copyright by Wydawnictwa Naukowe Instytutu Lotnictwa

\title{
THE ANALYSIS OF HOSPITAL HELICOPTER LANDING SITES LOCATION IN TERMS OF THEIR VIBROACOUSTIC IMPACT
}

\author{
dr inż. Andrzej Chyla \\ NOISE ACH \\ andrzej.chyla@gmail.com \\ Michał Bukała \\ SVANTEK Sp. z o.o. \\ m.j.bukala@gmail.com
}

\begin{abstract}
According to the applicable regulations, in the case of a decision on the location of an investment consisting in the construction and commissioning of a helicopter landing field, it is necessary to carry out an environmental impact assessment. At the same time, due to the emission of noise related to the expected change of acoustic climate parameters, the indicators required under the applicable law related to building acoustics and also impact of vibration on the structure of buildings should be taken into account. The article discusses particular groups of issues related to the assessment of the impact of helicopter landing field on the environment and the hospital building. On the basis of the presented results of analyzes, a postulate concerning the necessity of introducing a comprehensive assessment methodology, including specific groups of issues, was formulated.
\end{abstract}

Keywords: helicopter, aircraft, effective persist level, building vibration

\section{INTRODUCTION}

In many hospitals selected they were equipped with helicopter landing pads. So the problem of appropriate safeguards against their negative impact appeared. Despite the fact that they are „to the rescue" and are not subject to full assessment, practice indicates the need to take appropriate action. The article attempts to classify these negative impacts and attempts to comprehensively analyze them. This is an innovative approach to the subject and taking into account the ever-increasing requirements due to people staying in the building as well as the possibility of using modern medical equipment. Creating modern assessment methods and criterion values is simply a necessity today.

According to the applicable regulations, in the case of a decision on the location of an investment consisting in the construction and commissioning of a helicopter landing field, it is necessary to carry 
out an environmental impact assessment. At the same time, due to the emission of noise related to the expected change of acoustic climate parameters, the indicators required under the applicable law related to building acoustics and also impact of vibration on the structure of buildings should be taken into account. The article discusses particular groups of issues related to the assessment of the impact of helicopter landing field on the environment and the hospital building. On the basis of the presented results of analyzes, a postulate concerning the necessity of introducing a comprehensive assessment methodology, including specific groups of issues, was formulated.

\section{CLASSIFICATION OF THE ISSUE ACCORDING TO THE ACOUSTIC IMPACT}

The acoustic impact of aircraft is regulated by a number of national and international regulations. The choice of method and specific indicators to assess the extent of airborne noise impact zones is linked to the stated objective [1]. In the case of helicopters, the following groups of issues should be considered:

- helicopter acoustic certification,

- identification of noise and vibration sources in order to minimize acoustic impact,

- methods of estimating sound power and NPD parameters as necessary data for computational methods of preparing acoustic maps of impact zones,

- drawing up acoustic maps for helicopter airfields,

- evaluation of vibroacoustic parameters inside the helicopter,

- determination of acoustic climate parameters to assess the acoustic insulation of airborne sound and acceptable indoor sound levels.

Difficulties are caused by the use of different indicators for the assessment of airborne noise emissions. In many cases, the use of different methods and units of assessment has no substantive justification. The most important indicators used for acoustic evaluation can include:

- certification - Effective Noise Level EPNL,

- environment - equivalent $\mathrm{L}_{\text {Aeq }}$ sound level (for $\mathrm{L}_{\text {AeqD }}$ time of day, for $\mathrm{L}_{\text {AeqN }}$ time of night), $\mathrm{L}_{\mathrm{DWN}}$ 24-hour index, $\mathrm{L}_{\mathrm{AE}}$ exposure sound level,

- building acoustics - reliable sound level, maximum level, $\mathrm{L}_{\mathrm{Amax}}$ sound level, $\mathrm{R}_{\mathrm{w}}{ }, \mathrm{R}_{\mathrm{A2}}$ '

- identification of sources - sound pressure level,

- subjective evaluation of noise - volume, noise, annoyance.

Based on the assessment methods used and the research carried out, it should be assumed that a number of the terms quoted are used together. As a result, unintended inconsistencies or gaps in the methods used to assess airborne noise may occur.

\section{EXISTING LEGISLATION}

In order to avoid mistakes and assess objectively the phenomena related to air noise emissions, a number of legal acts are in force in Poland and worldwide. These are directives, acts, standards and instructions. The most important documents from the point of view of noise emission of helicopter airfields are: 


\section{General provisions}

- Directive 2002/49/EC of the European Parliament and of the Council of 25 June 2002.

- Annex 16 to the Convention on International Civil Aviation Environmental Protection Volume I Aircraft Noise

- Act of 27 April 2001. Environmental Protection Law (Journal of Laws 2018, item 799),

- International Standard ISO 20906 Acoustics - Unattended monitoring of aircraft sound in the vicinity of airports

\section{Environmental protection}

- Regulation of the Minister of the Environment of 14 June 2007 on permissible noise levels in the environment (Journal of Laws of 2014, item 112)

- Regulation of the Minister of the Environment of 16 June 2011 on the requirements for measurements of substance or energy levels in the environment by the road, railway, airport or port manager (Journal of Laws No. 140, item 824)

- Regulation of the Minister of the Environment of 10 November 2010 on the method of determining the value of the noise indicator $\mathrm{L}_{\mathrm{DWN}}$ (Journal of Laws No. 215, item 1414)

- Regulation of the Minister of the Environment of 1 October 2007 on the detailed scope of data included on acoustic maps and their arrangement and manner of presentation (Journal of Laws No. 187, item 1340).

- Regulation of the Minister of the Environment of 14 December 2006 on railroads and airports, the operation of which may cause negative acoustic impact on significant areas for which it is required to prepare acoustic maps and methods of defining the boundaries of areas covered by these maps (Journal of Laws of 2007 No. 1, item 8).

\section{Building acoustics}

- Regulation of the Minister of Infrastructure of 12 April 2002 on technical conditions to be met by buildings and their location - uniform text (Journal of Laws 2015, item 1422),

- PN-B-021516 Building acoustics Methods of A sound level measurement in buildings.

- PN-B-02151-2 Building acoustics. Protection against noise of rooms in buildings. Permissible sound values in rooms

- PN-B-02151-3 Building acoustics. Protection against noise of rooms in buildings. Acoustic insulation of partitions in buildings and acoustic insulation of building elements.

\section{Requirements}

- PN-ISO 3382 Acoustics Measurement of reverberation time in rooms in combination with other acoustic parameters

- PN EN ISO 140-5 Building acoustics. Measurement of sound insulation in buildings and building elements. Field measurements of airborne sound insulation of external walls and their elements.

- PN-EN ISO 717-1 Acoustics. Assessment of Sound Insulation in Buildings and Sound Insulation of Building Elements. Airborne sound insulation.

\section{Measurement of vibrations}

- PN-B-02170 Assessment of the harmfulness of vibrations transmitted through the substrate to buildings, 
- PN-B-02170 Assessment of the influence of vibrations on people in buildings.

In order to assess properly all aspects of the impact of a hospital helicopter landing field functioning, it is necessary to proceed in a comprehensive manner taking into account the above mentioned requirements.

In order to determine the proper environmental performance of the aerodrome, the provisions and procedures for determining whether the acceptable noise levels in the $\mathrm{L}_{\text {AeqD }}$ and $\mathrm{L}_{\text {AeqN }}$ environment are maintained should be applied. The next step is to determine the reliable sound level, which allows for the proper selection of the sound insulation index $\mathrm{R}_{\mathrm{A} 2}$ of building partitions located in the airborne noise impact zone. In the case of a helipad it is necessary to determine the structural vibration accelerations of hospital building elements and to measure the vibration accelerations in selected rooms with increased requirements for vibroacoustic comfort. Having a comprehensive knowledge of the actual impact of the landing field one can proceed to the assessment of the impact of the propagation routes of the vibroacoustic signal and its impact on people and the hospital building. This way of proceeding will be the most effective method of indicating the most important sources of noise and vibrations occurring during the proper operation of the hospital helicopter landing field.

\section{IMPACT OF AVIATION NOISE ON THE ENVIRONMENT}

The noise emitted by helicopters into the environment is a serious social problem. It is difficult for airports and airfields to coexist in harmony with conurbations, i.e. large concentrations of people, but sometimes, as in the case of hospital airfields, it is necessary.

The noise of a helicopter is fundamentally different from other types of aircraft noise. The basic element is its quasi-impulse character. This is due to the way in which acoustic disturbances are generated, and in particular the differences in the main sources of noise. These include the carrier rotor, tail rotor, power unit, reducer, compressor, exhaust manifold. A carrier rotor equipped with several blades, with a dominant sound pressure level in very low frequency ranges $(15-20 \mathrm{~Hz})$, which results from their rotational speed. Each blade has a different linear speed, depending on its azimuth relative to the main axis of the helicopter. In connection with this, the acoustic disturbance has:

- strong directivity,

- the essential tonal component and its harmonics,

- wide range of impact.

The tail rotor also significantly shapes the acoustic characteristics of the helicopter. The acoustic impact of this source depends on the design solution used. Tail rotors are tunnelled and not tunnelled. Depending on this, the sound pressure level is characterized by maximum values in the range of $40-63 \mathrm{~Hz}$ or in medium frequency bands [2]. The interaction between the two noise sources is also not without significance. 


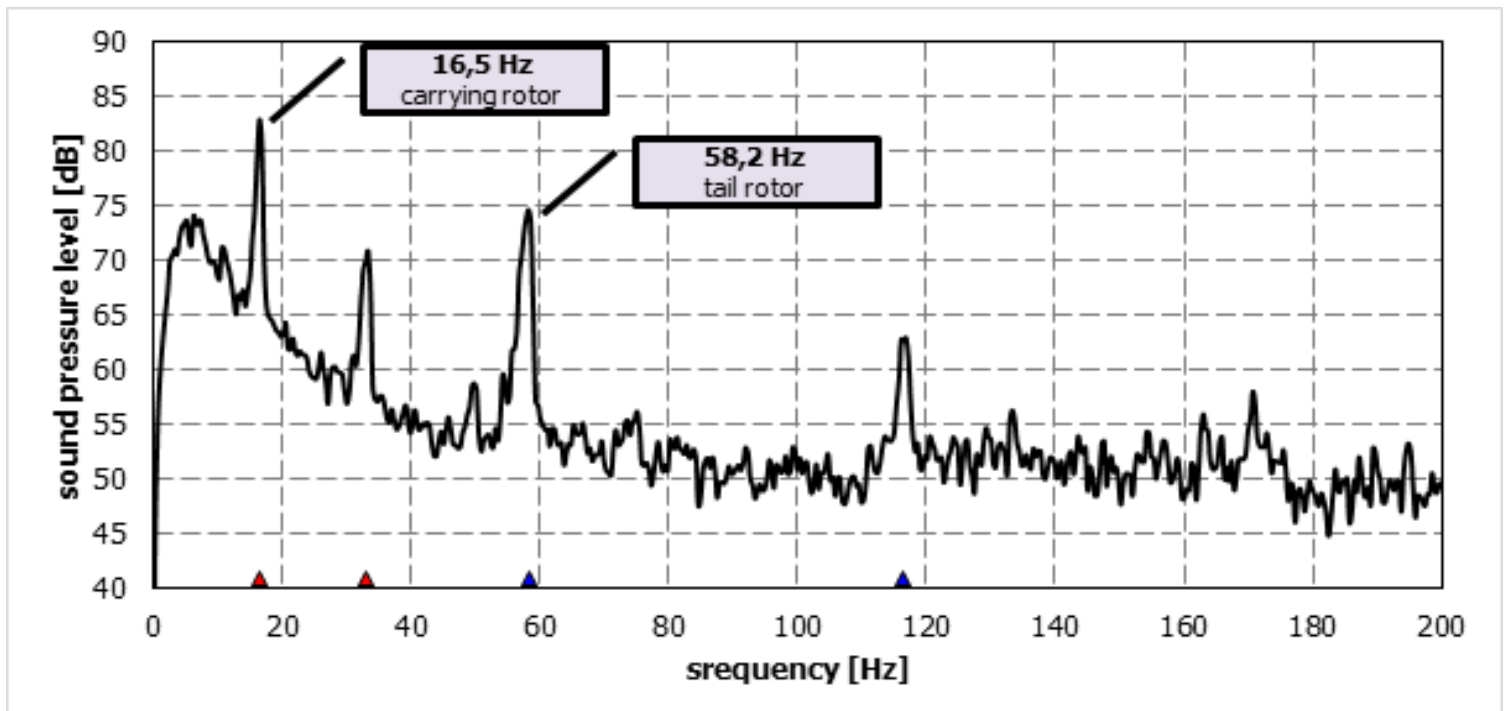

Figure 1: Helicopter noise spectrum with dominant noise sources and harmonics [3]

Apart from these phenomena, the trajectory of the helicopter's flight and the procedures of take-off and approach to landing differ significantly from aeroplane flight mechanics. The number of flight segments necessary to consider significantly increases when the helicopter operates from a small landing site, e.g. on the building roof. It is necessary, for example, to consider the hovering phase over the airfield and flight at low speed over or in the immediate vicinity of the heliport, both during climb and approach. Therefore, the mechanism of noise generation by the helicopter is necessary to use completely different methods of simulating the course of curves of uniform sound level affecting the environment.

Domestic and foreign experience with helicopter airfields clearly shows that the noise problem is one of the main barriers to their creation and, in the case of hospital airfields, their proper functioning. According to the regulations in force in Poland, it is necessary to draw an acoustic map of the heliport for the day that is least advantageous for acoustic reasons. On the basis of $\mathrm{L}_{\text {AeqD }}, \mathrm{L}_{\text {AeqN }}$ noise assessment indicators, the range of airborne noise nuisance is determined according to the binding measurement procedures, and then appropriate actions are taken in the case of exceeding excessive sound levels in the environment.

In order to prepare the impact assessment, it is necessary to prepare an acoustic map of the airfield with several input data variants in order to be able to choose the optimal solution. The assumed final variant can be controlled by the environmental authorities through periodical measurements carried out on the basis of the existing measurement procedures.

In order to draw up a proper acoustic map of a hospital airfield, it is recommended to conduct acoustic measurements during simulated take-offs, landings and flights together with the registration of the flight trajectory used by the LPR of the EC- 135 helicopter. Based on the obtained data, it is possible to prepare input data for the selected calculation procedure of the environmental noise zone range (INM or AEDT), e.g. for :

- helicopter flight (from the direction $284^{\circ}$ and from the direction $104^{\circ}$ )

- landing and take-off (in straight lines in the direction $284^{\circ}$ and $104^{\circ}$ )

- landing and take-off (rotating in the direction of $284^{\circ}$ ) 


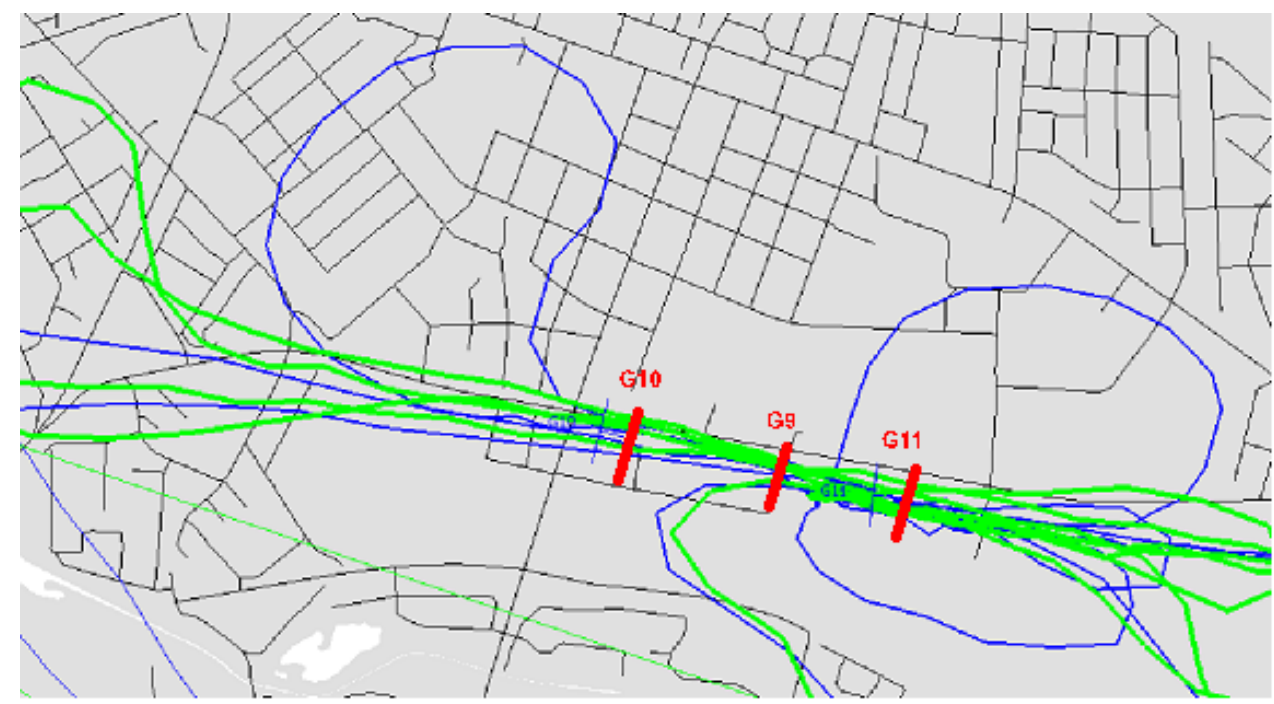

Figure 2 Recorded helicopter flight paths during measurements

As a result of the analysis of several variants of air traffic from the airfield it is possible to minimize the noise nuisance of each airfield. The results of calculations of variant analysis are presented in the form of curves of the same sound level for the daytime $\mathrm{L}_{\text {AeqD }}$ and night time $\mathrm{L}_{\text {AeqN }}$ for selected routes performed in reality of air operations.

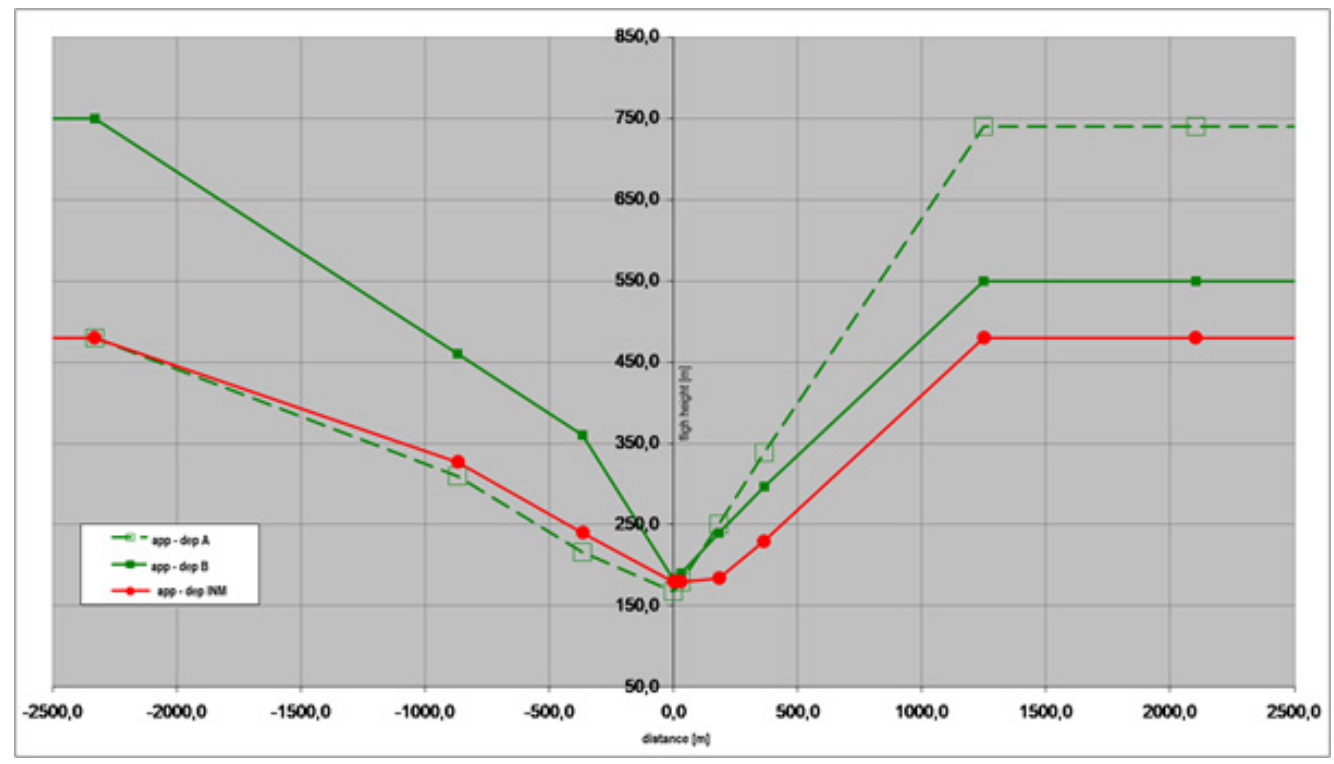

Figure 3: Nominal and actual flight profiles of EC 135 helicopter

A typical distribution of the range of noise zones around the hospital helicopter landing field for two approach alternatives is shown in Figures 4 and 5. 

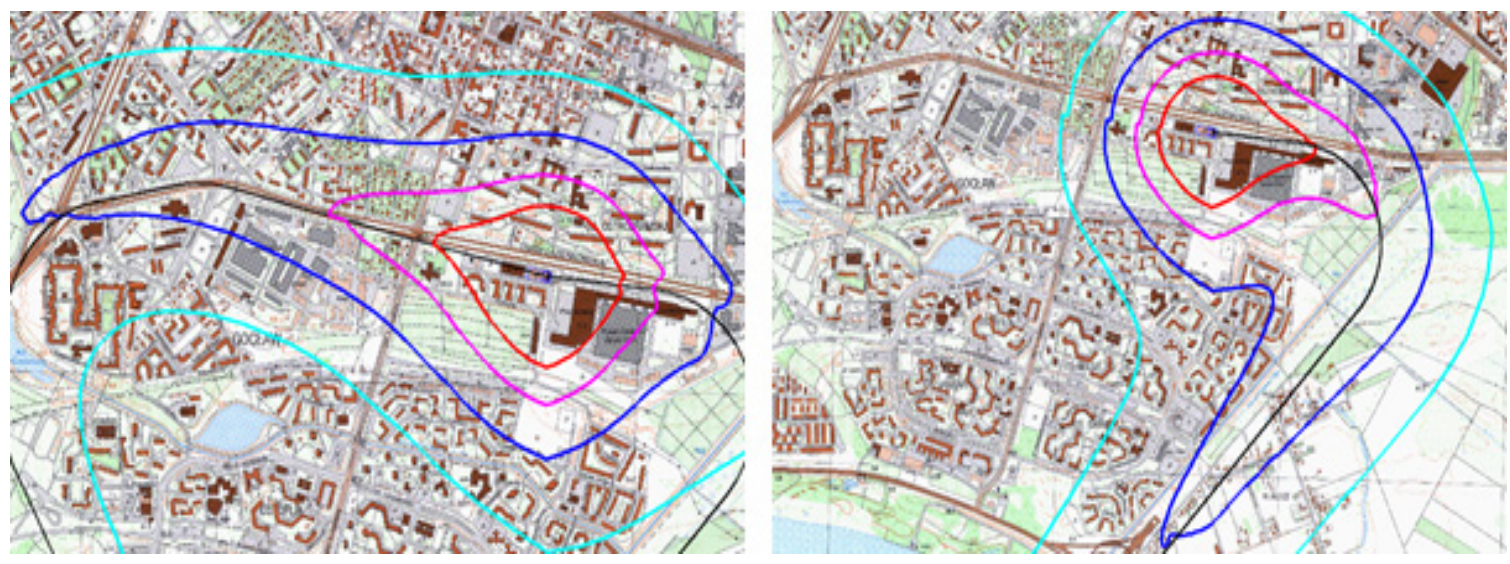

Figure 4: Sound curves of the EC-135 sanitary helicopter from landing west and take-off east and landing east and take-off east

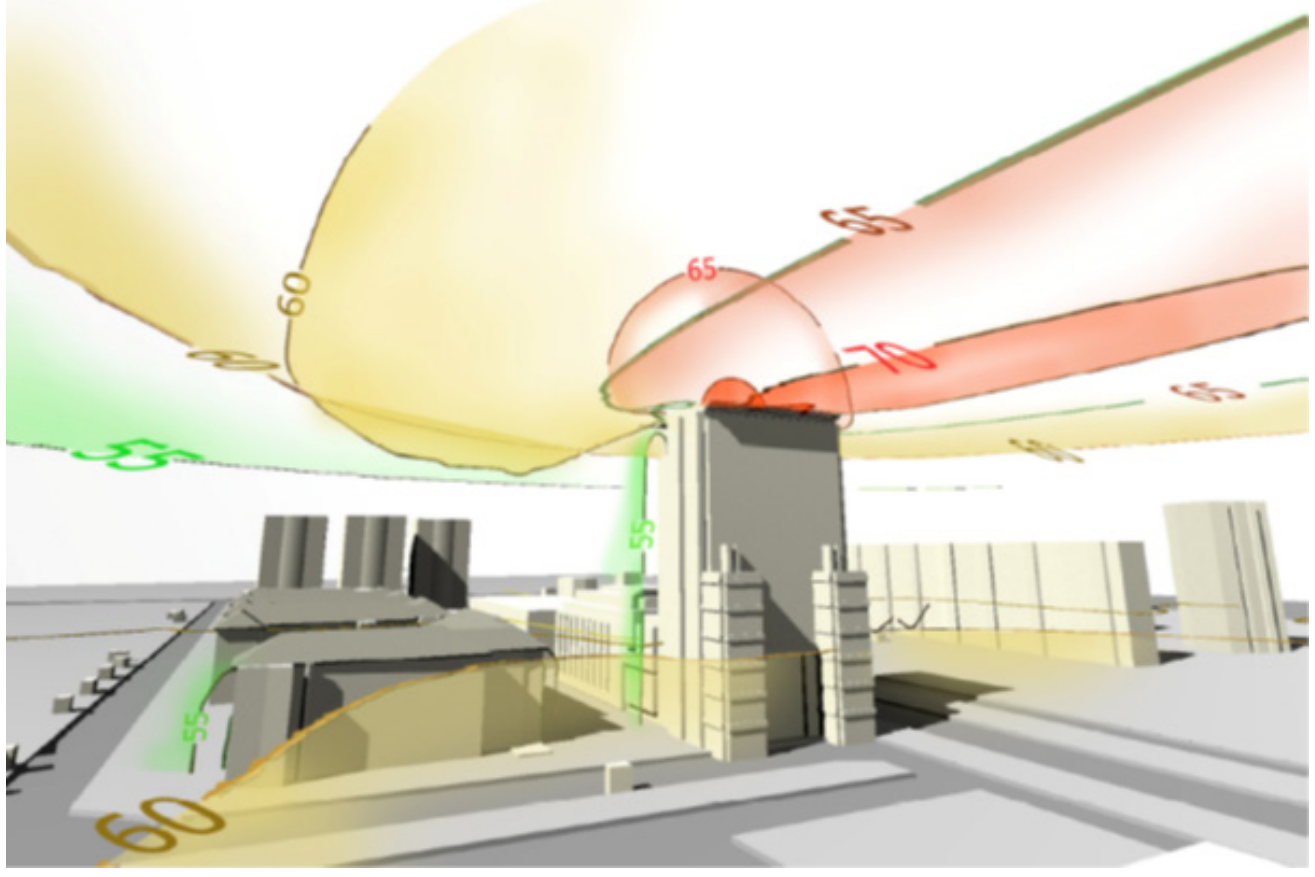

Figure 5: Translational Spatial Distribution of Equal Sound Level Curves for Daytime $\mathrm{L}_{\text {Aeq D }}$ [4]

The presented results of the assessment of noise zone range around hospital helicopter landing sites in the environment clearly indicate that this is not only a problem of spreading acoustic disturbances outward. An equally important issue is to determine a reliable sound level, which is the first element of the proper selection of acoustic insulation indicators from the air sounds of a hospital building façade which is under the influence of noise emission from the helicopter take-off and landing. 


\section{ASSESSMENT OF ACOUSTIC IMPACT DUE TO BUILDING ACOUSTICS}

In practice, a hospital helicopter airfield is always located in the vicinity of the hospital building or directly on it. In each of these cases, the question arises of the correct design of the façade of the building, which is influenced by the emission of airborne noise. The essential elements to be taken into account are

- the minimum flight distance of the helicopter from the façade of the building or its elements,

- uneven distribution of the acoustic wave on the façade of the building and its elements,

- very high requirements for permissible sound levels in hospital rooms, especially at night,

- percentage share of the total façade surface area of the transverse elements,

- noise impact in the very low frequency range,

- the location of hospital rooms that are particularly sensitive to the emission of noise,

- the method of connecting the structural elements of the hospital building with the structure of the airstrip.

From the point of view of building acoustics and the influence of vibroacoustic phenomena on the hospital building, two variants of the applied solutions should be distinguished: an airfield located near the hospital complex or an elevated airfield located directly on the hospital building.
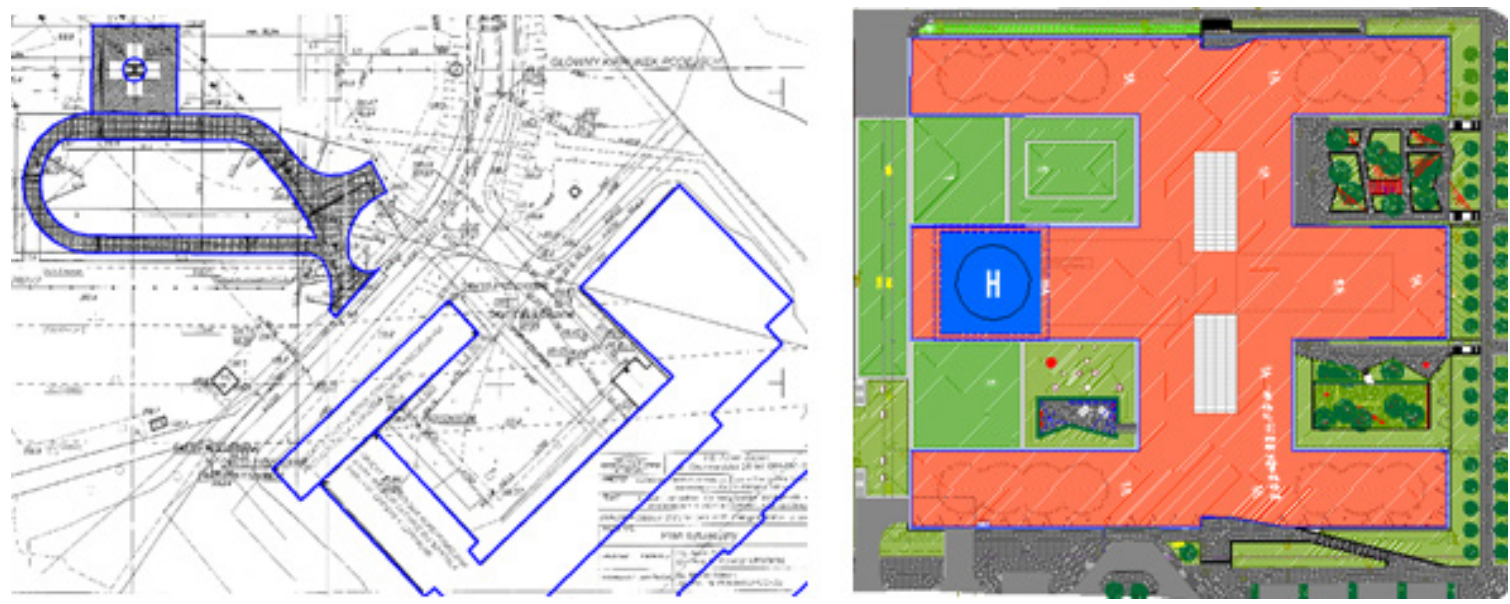

Figure 6: Two options for the location of a hospital helicopter landing site [5]

The procedure for the selection of materials for an external wall structure requires, in the first phase, the determination of a reliable sound level for the time of day and night, occurring $2 \mathrm{~m}$ in front of the building façade. Based on the volume of the receiving room and the area of the building envelope in this room, the required sound insulation index $\mathrm{R}_{\mathrm{A} 2}$ is then calculated.

According to the current regulations, because the airfield is usually located at a distance of e.g. $280 \mathrm{~m}$ from residential buildings and e.g. about $70 \mathrm{~m}$ from the nearest building of a hospital complex, due to the noise emission during the take-off and landing of helicopters, it is necessary to increase the acoustic insulation of external walls of these buildings from the side of the airfield in accordance with the PN-B-02151-3 standard. 
Table 1: Required sound insulation values of the hospital building envelope (PN-B-02151-3:1999)

\begin{tabular}{|c|c|c|c|c|c|c|c|c|}
\hline \multirow{3}{*}{$\begin{array}{l}\text { Building } \\
\text { type }\end{array}$} & \multirow{3}{*}{$\begin{array}{l}\text { Outdoor } \\
\text { partition } \\
\text { in the room }\end{array}$} & & \multicolumn{6}{|c|}{$\begin{array}{l}\text { Required weighted apparent sound reduction index value } \mathrm{R}_{\mathrm{A} 2} \text { in decibels, } \\
\text { depending on the A-weighted sound level in decibels during day/night } \\
\text { outside the building }\end{array}$} \\
\hline & & day & to 45 & $\begin{array}{c}\text { from } 46 \\
\text { to } 50\end{array}$ & $\begin{array}{c}\text { from } 51 \\
\text { to } 55\end{array}$ & $\begin{array}{c}\text { from } 56 \\
\text { to } 60\end{array}$ & $\begin{array}{c}\text { from } 61 \\
\text { to } 65\end{array}$ & $\begin{array}{c}\text { from } 66 \\
\text { to } 70\end{array}$ \\
\hline & & night & to 35 & $\begin{array}{l}\text { od } 36 \\
\text { do } 40\end{array}$ & $\begin{array}{l}\text { od } 41 \\
\text { do } 45\end{array}$ & $\begin{array}{l}\text { od } 46 \\
\text { do } 50\end{array}$ & $\begin{array}{l}\text { od } 51 \\
\text { do } 55\end{array}$ & $\begin{array}{l}\text { od } 56 \\
\text { do } 60\end{array}$ \\
\hline Hospital & $\begin{array}{l}\text { Medical } \\
\text { examination }\end{array}$ & rooms & 20 & 23 & 23 & 28 & 33 & 38 \\
\hline
\end{tabular}

Table 2: Examples of sound level results for the selection of acoustic insulation of a hospital building façade

\begin{tabular}{|l|c|c|c|}
\hline & $\begin{array}{c}\text { daytime } \\
\mathrm{L}_{\text {Aeq D }}[\mathrm{dB}]\end{array}$ & $\begin{array}{c}\text { night time } \\
\mathrm{L}_{\text {Aeq N }}[\mathrm{dB}]\end{array}$ & $\mathrm{L}_{\text {Amax }}[\mathrm{dB}]$ \\
\hline Façade variant 1 & $65-70$ & $61-65$ & 82 \\
\hline Façade variant 2 & $71-75$ & $61-65$ & 87 \\
\hline
\end{tabular}

On the basis of the values of the noise level from air operations in accordance with the applicable standard, the required RA2 resultant sound insulation values for external partitions are determined:

- Façade variant $1 \mathrm{R}_{\mathrm{A} 2}=38 \mathrm{~dB}$

- Façade variant $2 \mathrm{R}_{\mathrm{A} 2}=40 \mathrm{~dB}$

In the case when the window area does not exceed $50 \%$ of the total wall area, the sound insulation index for the solid part of the wall and for the window, determined in laboratory conditions, should not be lower than:

Façade variant 1

- Full part $\mathrm{R}_{\mathrm{A} 2}=47 \mathrm{~dB}$

$-\mathrm{R}_{\mathrm{A} 2}$ window $=37 \mathrm{~dB}$

Façade variant 2

- Full part $\mathrm{R}_{\mathrm{A} 2}=49 \mathrm{~dB}$

$-\mathrm{R}_{\mathrm{A} 2}$ window $=39 \mathrm{~dB}$

Despite the acoustic insulation of the external wall, which was selected according to the standard guidelines, in many cases (especially when the façade was stimulated by helicopter noise), it turns out that the acoustic climate in the rooms is not appropriate. A number of examples can be cited where the relevant insulation values of both the solids and the windows are completely sufficient and the permeation of noise into the hospital rooms is too high. In this case, it is possible to measure the sound pressure level of the places with the least insulation for specific helicopter noise frequencies that are not included in the standard insulation assessment.

A similar measurement technique can be used to identify the main sources of helicopter noise. 


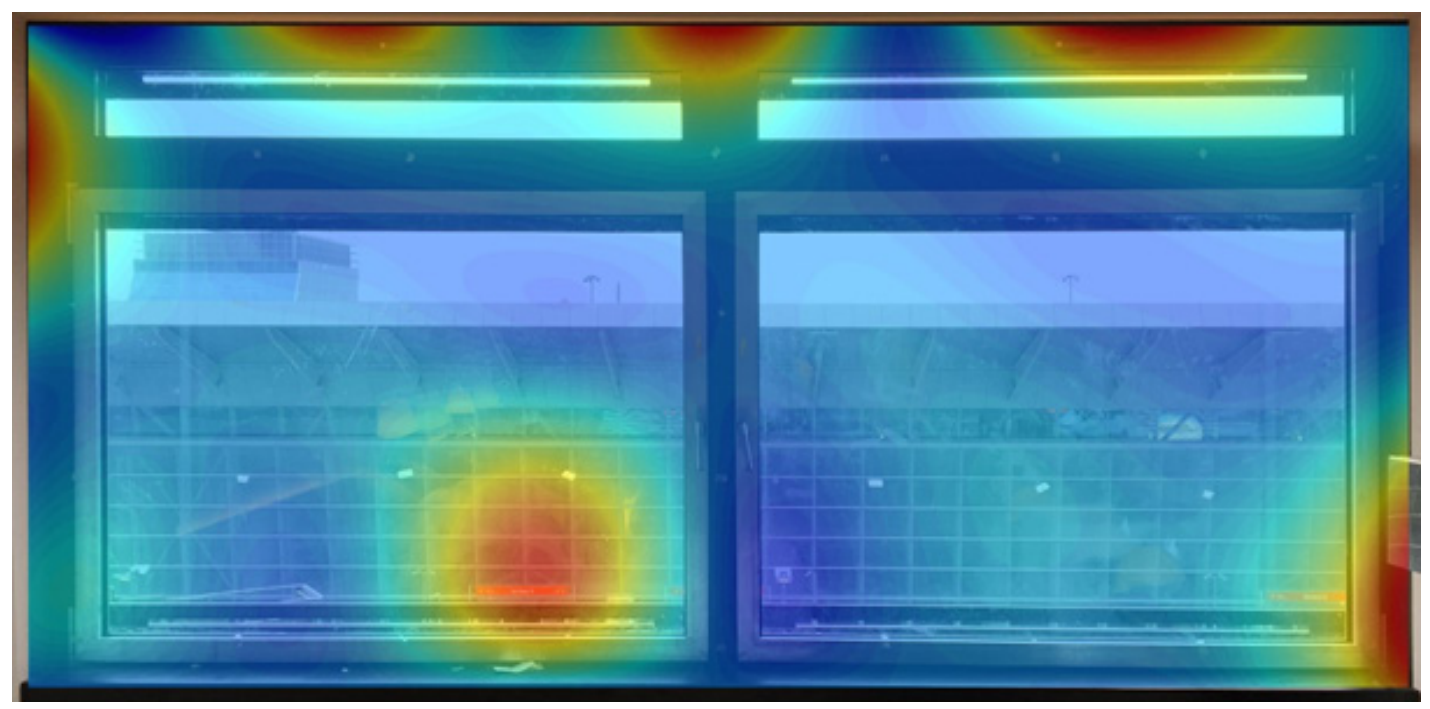

Figure 7: Diagnostics of the sound insulation of the building façade using the sound intensity technique [6]

The obligation to assess the choice of insulation of a hospital façade results from the necessity to ensure appropriate acoustic comfort in the rooms of a functioning hospital. In accordance with the binding PN-B-02151-2 standard, the permissible equivalent A-weighted sound level of noise penetrating into rooms intended for human occupancy is determined separately for day and night time, and both conditions must be met simultaneously. For the daytime, i.e. between 6.00 and 22.00, the equivalent level is assumed for eight most unfavourable hours, and for the night time $(22.00-6.00)$ for $1 / 2$ hour. The A-weighted sound level in hospital patient rooms should not exceed the $\mathrm{L}_{\text {Aeq }}$ equivalent of $35 \mathrm{~dB}$ for the time of day and $30 \mathrm{~dB}$ for the time of night.

Compliance with the equivalent sound level requirement, especially for 8 hours of daytime, may not provide adequate acoustic comfort in hospital rooms. The nature of the impact of the noise emitted by the use of a helicopter airfield due to its short-term operation, the predominance of low frequency sound pressure levels in the spectrum and the occurrence of vibroacoustic phenomena significantly increases its perceptible annoyance to humans. There is also another aspect of correct assessment of the impact of hospital helicopter landing sites, which is the propagation of vibrations in the range from $1 \mathrm{~Hz}$ to $80 \mathrm{~Hz}$.

The analysis of the vibration spectrum takes into account the following recorded values:

- envelopes of peak values (maximum spectrum of peak values of peak accelerations of vibrations in third bands)

- mean square values (spectrum of mean square values of vibration accelerations in third bands).

An example of a recorded vibroacoustic signal in the form of a time course is shown in the Figure. 


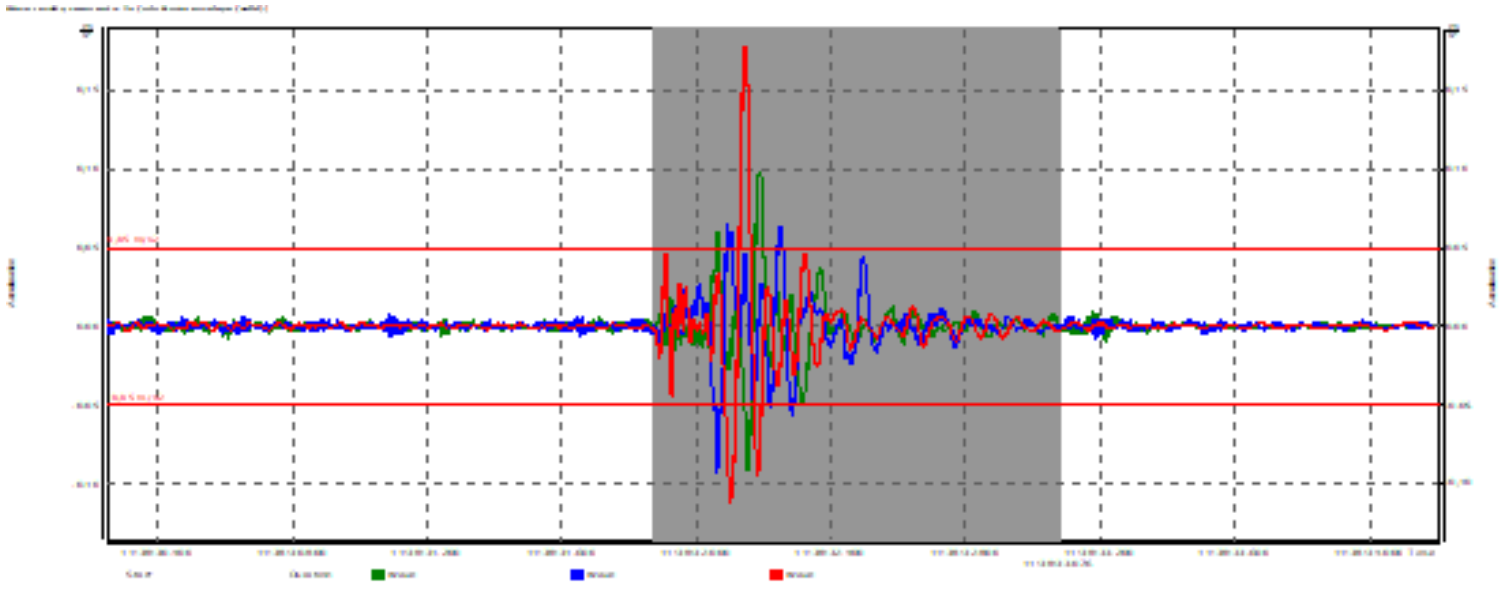

Figure 8: Example of the time course of a recorded vibroacoustic signal [7]

The analysis of the raster signal enables the assessment of the influence of vibrations on the building according to the laws applicable in Poland.

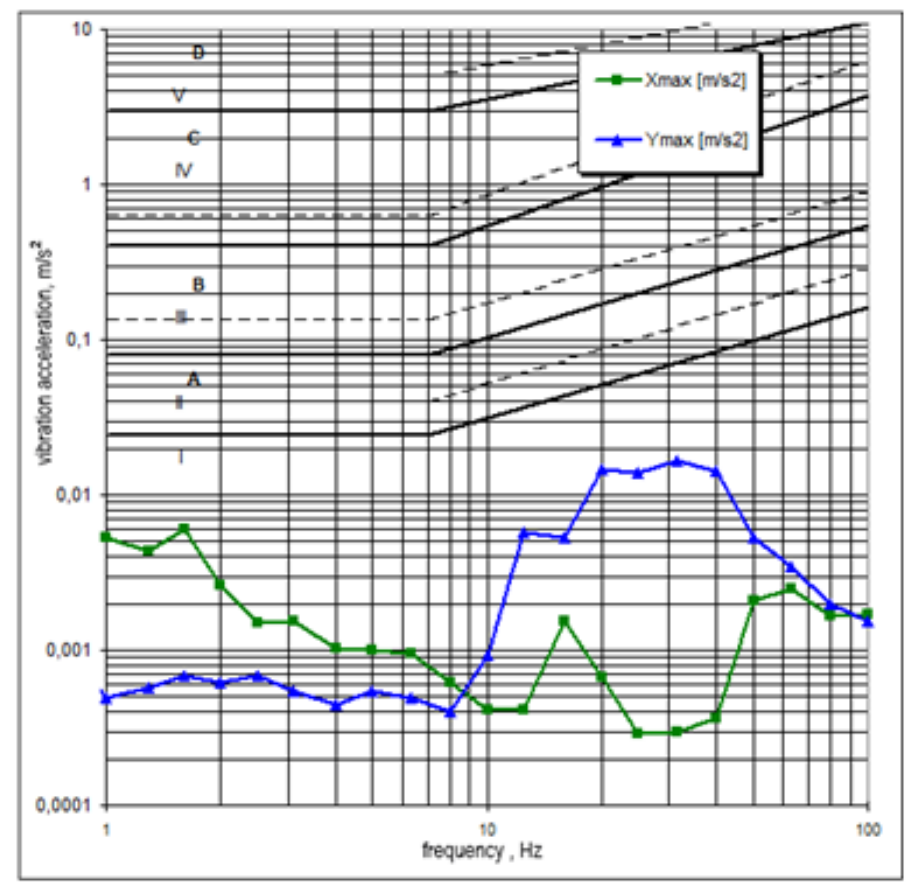

Figure 9: Assessment of the impact of vibration on a building using SWD scales [7]

Due to the established vibration thresholds and their impact on people in hospital buildings, daytime vibrations can be used to evaluate acoustic comfort, especially in patient rooms and other protected rooms. 


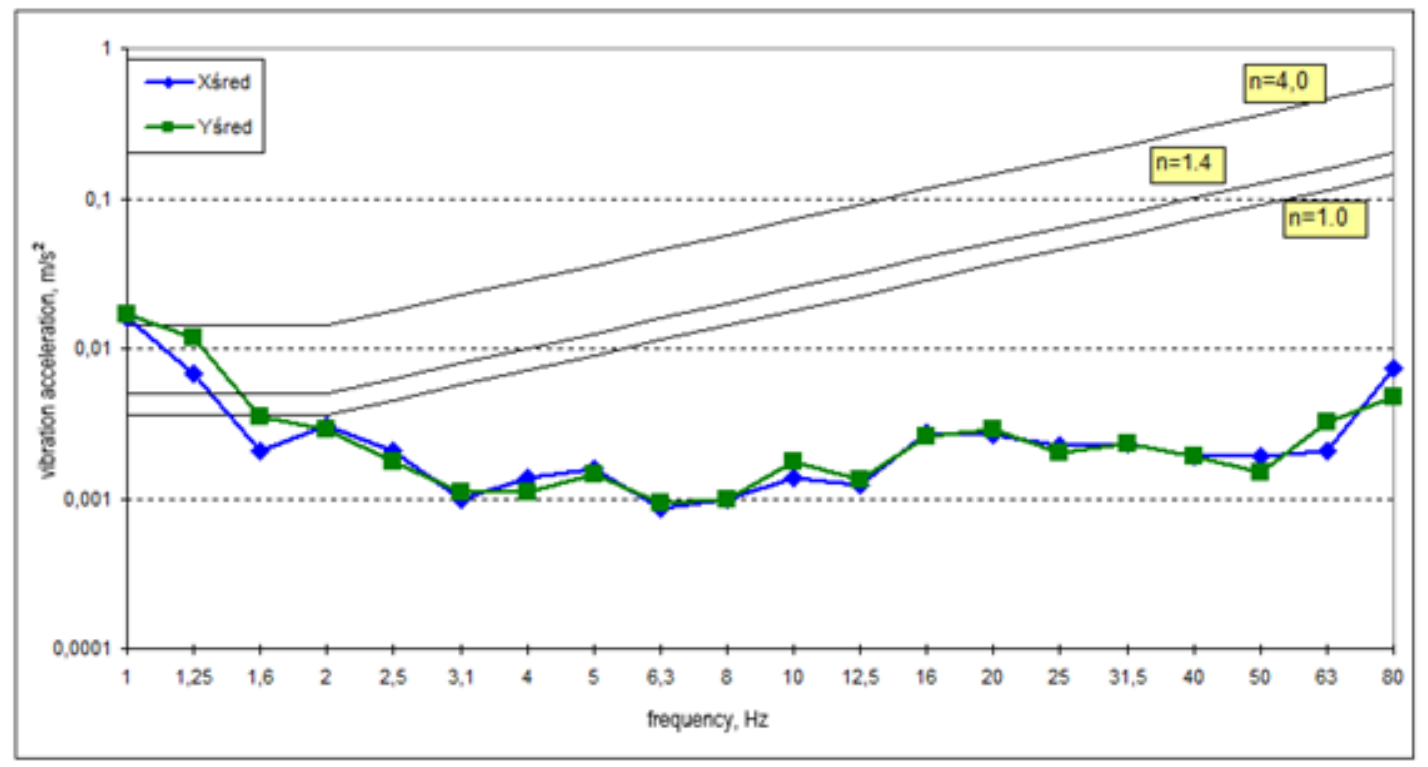

Figure 10: Evaluation of vibration comfort of people staying in rooms [7]

The objective assessment of the impact of vibrations on people in particular, based on the measured acceleration values in a hospital building, can and usually differs significantly from the subjective assessment. This is particularly evident with simultaneous exposure to noise and vibration. In the case of a hospital helicopter landing site located directly on a hospital building, all known factors increasing annoyance due to vibroacoustic phenomena play a very important role and should be taken into account in the design process and, first of all, in the selection of appropriate vibroacoustic protection.

Vibrations transmitted to the structure of the building also affect the precise diagnostic equipment, such as computer tomography or scanners for MRI and fMRI magnetic resonance imaging. Vibrations can affect the proper functioning of the equipment and, consequently, the quality of the test results. In accordance with the guidelines of the PN-B-02170 standard, based on measurements of the vibration velocity of the device base with the manufacturer's guidelines, or if there are no such guidelines, based on the general principles described in the standard.

\section{SUMMARY AND CONCLUSIONS}

The basic element in the assessment of the hospital impact of a helicopter landing site is the identification of the most important sources of noise and vibration and the ways of their propagation.

Considering the noise emission occurring during the air operations related to the use of the hospital landing site of the helicopter, one can conclude that there are a number of very complicated sources emitting the sound pressure level. The main element is, of course, the operation of the carrier rotor with particular emphasis on the phenomenon of pale slap. Then, a large proportion of the noise emitted by the tail rotor is visible in the noise spectrum. In the following phases of flight, the noise from the propulsion unit also plays an important role. The analysis of these phenomena can be considered as a superposition of elementary acoustic sources depending on the number of waves on the blades of the rotor and tail rotor: 
- monopoly - operation of the carrier rotor,

- dipole - pulsations on the carrier rotor and tail rotor blades,

- quadrupole - interaction of outgoing whirls from the carrier rotor blades.

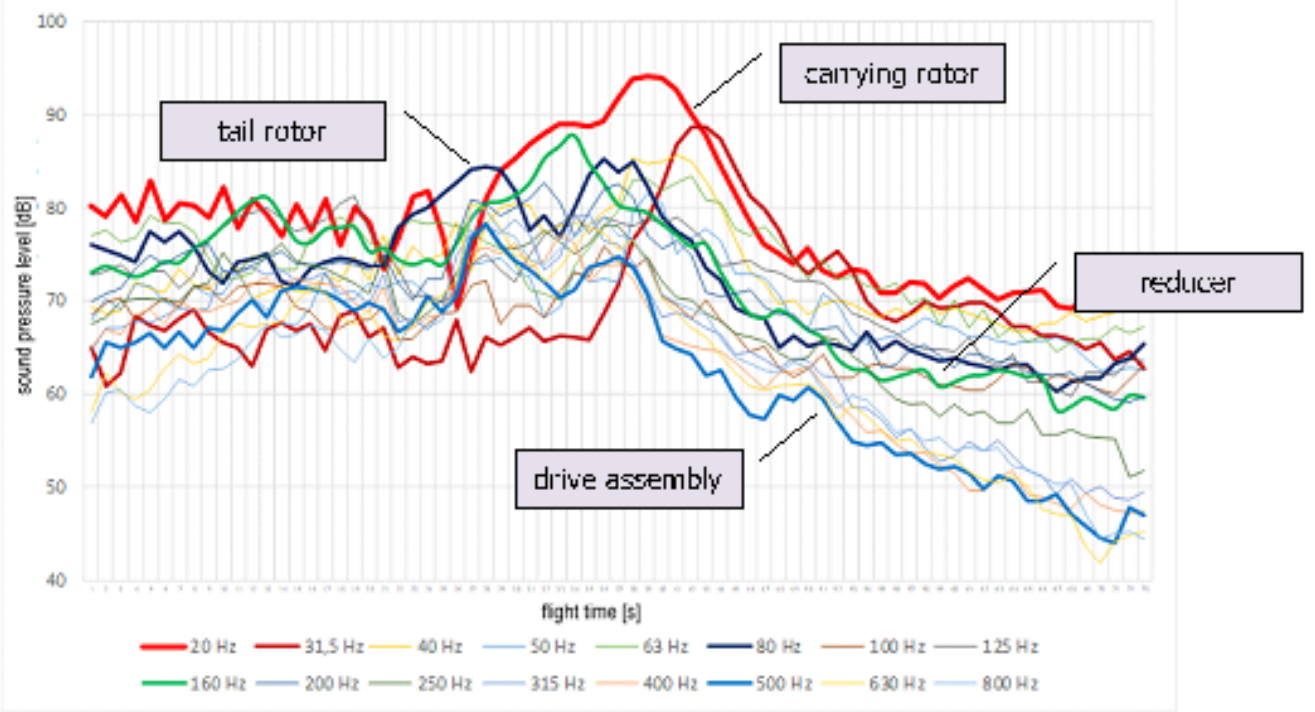

Figure 11: Identification of the main helicopter noise sources

This problem has its consequences in the way of interpretation, possibilities of reducing the impact and range of airborne noise zones.

When assessing the impact of noise emitted by a functioning hospital helicopter landing field, the first step is to determine the curves of the same sound level in the environment. The assessment of this noise allows to determine a reliable sound level, which gives the possibility to choose the appropriate resultant sound insulation from the airborne sound of external walls of hospital buildings.

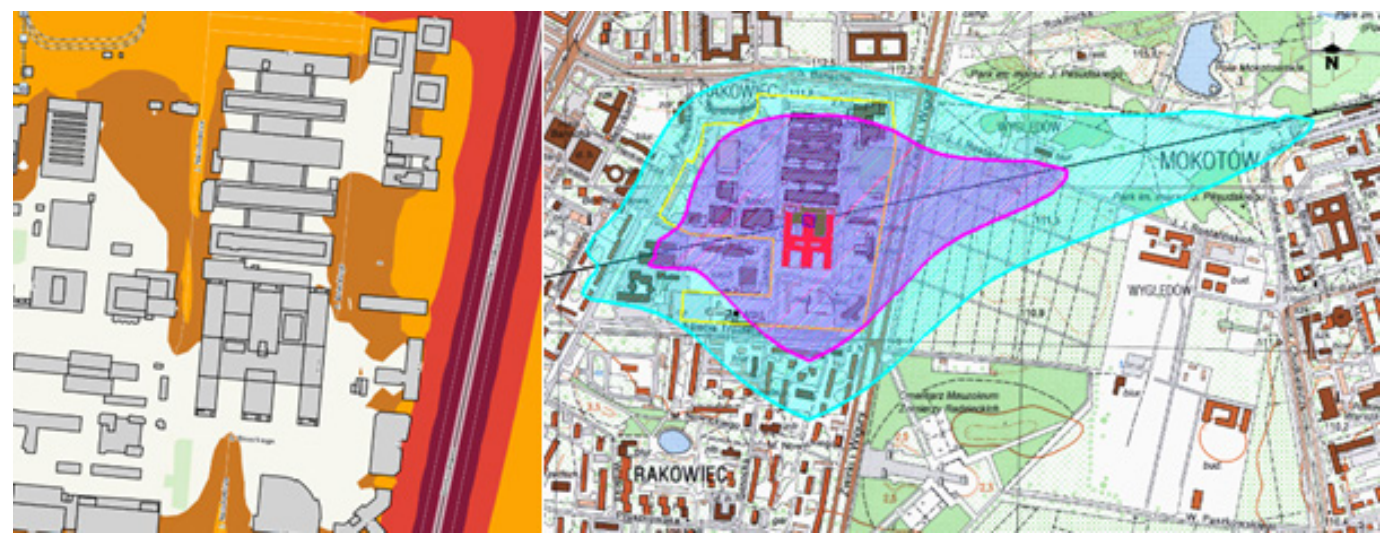

Figure 12: Acoustic map of Warsaw without considering noise from helicopter landing field and distribution of sound level curves for landing field [5] [8] 
It is necessary to introduce the obligation to select the R'A2 sound insulation index into the design process. This problem should be taken into account in the proper acoustic protection of hospital complex buildings. This procedure is necessary for every helicopter hospital airfield.

A more complex situation is to consider the impact of vibrations on the building, medical equipment and people in the rooms of a hospital building. The assessment may reveal that the existing legislation will not be sufficient to make the necessary structural changes. At present, there is insufficient data to take into account vibroacoustic phenomena in the case of elevated helicopter landing sites permanently associated with a hospital building. It may be necessary to apply methods and requirements administered in other countries. At the initial stage of the problem identification, an attempt may be made to apply the requirements of DIN 4150-3:1999-02 Structural vibration. Part 3: Effects of vibration on structures and FTA-VA-90-1003-06 United States of America, Federal Transport Administration, Transit Noise and Vibration Impact Assessment,

In view of the very complex issue related to the impact of vibroacoustic phenomena in the low frequency range, it is necessary to undertake research in order to develop appropriate assessment methods and criteria.

\section{LITERATURE}

[1] J. S. Newman, E. J. Rickley, D. A. Levanduski i S. B. Woolridge, „Analysis of helicopter noise data using intenational helicopter noise certification procedures," FAA, Washington D.C., 1986.

[2] A. Chyla, „Some Mathematical Models for Describing the Acoustic Properties of Airscrews," Works of the Institute of Aviation, nr 91, pp. 29-62, 1982.

[3] A. Chyla i M. Bukała, Certification measurements of MI-8 helicopter, Warsaw: SVANTEK, 2017.

[4] NOISE ACH, Environmental impact report for the planned investment involving the construction of a helicopter landing pad in an office building Ostrobramska 77 in Warsaw, Warsaw, 2010.

[5] NOISE ACH, Noise analysis from aircraft operations for a planned investment involving the construction of a helicopter landing pad on the roof of a pediatric hospital at the Medical University of Warsaw, Warsaw, 2010.

[6] A. Chyla i M. Bukała, „Tests of sound insulation from air sounds of an external wall fragment of a $5^{*}$ hotel building at the Warsaw-Okecie Airport," Warsaw, 2016.

[7] A. Chyla i M. Bukała, „Measurement report on vibrations affecting the building and people in buildings from micro-explosions for the construction of the Koszalin and Sianów bypass on S-6," Warsaw, 2017.

[8] BMTcom Sp. z o.o.;SVANTEK Sp. z o.o.;PVO Sp. z o.o, „Acoustic map of the Capital City of Warsaw," 2017. [Online]. Available: http://mapaakustyczna.um.warszawa.pl.

[9] J. S. Newman, E. J. Rickley i T. L. Bland, „Helicopter Noise Exposure Curves for use in Environmental Impact Assessment," FAA, Washington D.C., 1982.

[10] D. Keast, E. Eldred i J. Purdum, „Heliport Noise Model Version 1 User's Guide,” FAA, Washington D.C., 1988.

[11] D. B. Hanson, „Study of noise and inflow distortion sources in the NASA QF-1B fan using measured blade and vane pressures," National Aeronautics and Space Administration, Washinton D.C., 1977.

[12] K. Dziuba, A. Chyla i Z. Czerwiński, „A Statistical Model of Helicopter Noise,” Works of the Institute of Aviation 112-113, pp. 75-107, 1988.

[13] A. Chyla, „Statistical analysis of the impact of operating parameters on aeroacoustic effets,” Works of the Institute of Aviation, nr 102, pp. 63-90, 1985. 